REVISTA EVIDENCIAÇÃO CONTÁBIL \& FINANÇAS

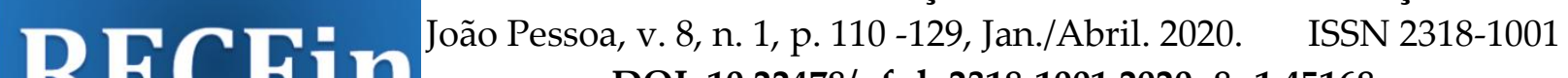

DOI: 10.22478/ufpb.2318-1001.2020v8n1.45168

Disponível em: $\underline{\text { http://periodicos.ufpb.br/ojs2/index.php/recfin }}$

\title{
EFICIÊNCIA TRIBUTÁRIA DOS PAÍSES-MEMBROS DA OECD E BRASIL PARA A GERAÇÃO DE EDUCAÇÃO
}

\section{TAX EFFICIENCY OF OECD MEMBER-STATES AND BRAZIL IN THE IMPROVEMENT OF EDUCATION}

\author{
Marilene Feitosa Soares \\ Doutorado em Ciências Contábeis (Universidade do Minho - Portugal) \\ Universidade Federal do Ceará \\ marilene.feitosa@ufc.br \\ Lúcia Lima Rodrigues \\ Doutorado em Ciências Empresariais (Universidade do Minho - Portugal) \\ Universidade do Minho \\ lrodrigues@eeg.uminho.pt \\ Mário José Macedo Marques \\ Doutorado em Ciências Contábeis (Universidade do Minho - Portugal) \\ Universidade do Minho \\ mmarques@eeg.uminho.pt
}

\section{RESUMO}

Objetivo: Medir o nível de eficiência dos países-membros da OECD e Brasil na alocação da receita tributária para a geração de educação.

Fundamentos: $\mathrm{O}$ estudo baseia-se na Teoria da Tributação Ótima, que associada ao Princípio da Eficiência Pública, explica que a carga tributária é considerada justa, quando é direcionada para a garantia do bem-estar, atribuindo-se o menor custo para a sociedade. Nesse sentido, a pesquisa classifica como eficientes, os países que aplicam o mínimo de recursos tributários para o alcance de elevados níveis de educação.

Métodos: A pesquisa é de natureza descritiva, documental e com abordagem quantitativa, empregando-se a técnica multivariável e não paramétrica Data Envelopment Analysis [DEA] no modelo Charnes, Cooper e Rhodes [CCR] e o método hierárquico de clusters.

Resultados: Os resultados revelaram que Letônia, Coreia do Sul, México, Chile, Estônia, Irlanda, Islândia, Estados Unidos, Austrália e Suíça foram os países que alcançaram maior nível de eficiência na alocação das receitas tributárias em favor da educação, ao passo que, Itália, França, Dinamarca, Suécia, Brasil, Áustria, Bélgica, Turquia, Alemanha e Noruega expressaram menor nível de eficiência. Adicionalmente, a pesquisa evidenciou que os países com maiores receitas tributárias não são, necessariamente, os mais eficientes na aplicação desses recursos em favor da educação.

Contribuições: A pesquisa amplia os estudos sobre a mensuração de eficiência na área da Contabilidade e auxilia gestores na administração dos recursos públicos e tomada de decisões, ao permitir identificar fragilidades e melhorias na alocação de receitas tributárias. 
Palavras-chave: Receita Tributária. Eficiência. Educação. DEA.

\begin{abstract}
Objectives: To measure the efficiency levels of Brazil and member-states of the OECD in the allocation of tax revenue for education improvement.

Background: The paper is based on the Optimal Tax Theory, and on Public Efficiency Principle. The theoretical framework explains that the tax revenue is considered fair when it is directed to guarantee the improvement in the well-being, with the lower cost to the society. This way, the study classifies as efficient, countries which apply minimum tax resources to reach high levels of education.
\end{abstract}

Methods: This research is descriptive, documentary and adopts a quantitative approach, using the non-parametric Data Envelopment Analysis [DEA] technique (the Charnes, Cooper and Rhodes [CCR] model) and the hierarchical cluster method.

Results: The results revealed that Latvia, South Korea, Mexico, Chile, Estonia, Ireland, Iceland, the United States, Australia and Switzerland were the countries that achieved the highest level of efficiency in allocating tax revenues for education. On the other hand, Italy, France, Denmark, Sweden, Brazil, Austria, Belgium, Turkey, Germany and Norway expressed lower levels of efficiency. Additionally, the survey showed that countries with higher tax revenues are not necessarily the most efficient in applying these resources to education.

Contributions: The research has broadened the studies on efficiency measurement in accountancy area. It helps managers in the administration of public resources and decision making since it permits to identify weaknesses and to improve the allocation of tax revenues.

Key-words: Tax Revenues. Efficiency. Education. DEA.

\title{
1 INTRODUÇÃO
}

A educação está diretamente relacionada com o desenvolvimento de um país e é um direito humano fundamental, essencial para transformar vidas, erradicar a pobreza e impulsionar o desenvolvimento sustentável (UNESCO, 2017).

De acordo com o Programa das Nações Unidas para o Desenvolvimento [PNUD] (2013, p. $27)$, “[...] os países podem investir suas receitas na educação ou em armas de guerra”. Enfatiza ain$\mathrm{da}$, a responsabilidade de todas as nações de respeitar, proteger e promover o bem-comum, reconhecendo que cada um é responsável pelo seu próprio desenvolvimento social (PNUD, 2017).

O acesso aos serviços públicos de alta qualidade continua sendo preocupação universal. No Fórum Mundial sobre a Educação, realizado em Dakar (Senegal) em 2000, 164 países se comprometeram a melhorar a qualidade do ensino e assegurar uma educação inclusiva e equitativa no período de 2000 a 2015, no entanto, apesar de $83 \%$ das constituições nacionais disporem de uma previsão legal sobre o direito à educação, ainda há cerca de 781 milhões de analfabetos no mundo e milhares de crianças e adultos fora das escolas (UNESCO, 2017).

A função social do tributo é a de garantir uma vida saudável para a população (Beuren, Moura, \& Kloeppel, 2013) e os governos devem administrar os recursos de maneira eficiente para atender as necessidades coletivas e fornecer educação de boa qualidade.

A Contabilidade, como ciência social, possibilita a geração de informações amplas e valiosas, capazes de transformar o mundo, podendo influenciar diretamente nas questões sociais. No âmbito da ciência contábil, a Teoria da Tributação Ótima explica que a tributação ideal é aquela que é aplicada para a promoção do bem-estar social, sem onerar excessivamente os contribuintes de tributos (Payeras, 2008; Maydew, 2001; Alm, 1996). 
O Princípio da Eficiência Pública destaca a importância do Estado oferecer serviços de qualidade, de forma que alcance resultados satisfatórios e atenda as necessidades sociais da comunidade (Schachter, 2007; Firmino, 2013).

À luz da Teoria da Tributação Ótima e do Princípio da Eficiência Pública, o estudo objetiva medir o nível de eficiência dos países-membros da Organization for Economic Cooperation and Development [OECD] e Brasil na alocação da receita tributária para a geração de educação, considerando que, países eficientes são os que alocaram o mínimo de recursos tributários e alcançaram elevados níveis de satisfação educacional. Neste contexto, a pesquisa demanda responder à seguinte questão de investigação: Qual o nível de eficiência dos países-membros da OECD e Brasil na alocação da receita tributária para a geração de educação?.

É depreensível o fato de que a combinação entre a receita tributária, uma das principais fontes de financiamento do Estado para a promoção do bem-estar social (Ferrer, 2014; Grimm et al., 2009) e os indicadores de educação permite revelar se os recursos públicos foram utilizados com eficiência nesta área.

Para identificar o uso eficiente de algum recurso, é necessário definir uma referência que permita medir fronteiras de eficiência. Assume-se, nesta demanda, como medida de eficiência, a Análise Envoltória de Dados ou Data Envelopment Analysis [DEA], que consiste numa técnica multivariável, não paramétrica, que utiliza a programação linear para comparar unidades tomadoras de decisões, Decision Making Unit [DMU], permitindo incorporar várias entradas (inputs) e saídas (outputs) para valor único. Os dados foram tratados posteriormente, utilizando-se o dendograma e gráfico de dispersão.

Rezende, Slomski e Corrar (2005) ressaltam a necessidade da realização de estudos no âmbito da Contabilidade que demonstrem a efetiva aplicação dos recursos públicos, bem como a influência positiva no desenvolvimento social, considerando que a chave de sucesso numa economia mundial mais competitiva e dinâmica reside na melhoria do bem-estar social (PNUD, 2013). Assim, este trabalho se justifica pela relevância do tema no contexto social e contábil, permitindo revelar aos gestores e à sociedade se as receitas originadas de pagamento de tributos estão sendo bem aplicadas na promoção do bem-estar educacional. Decorre, pois, deste ponto, a importância de se proceder a um diagnóstico sobre a gestão dos recursos públicos.

A investigação está dividida em cinco seções, iniciando com a introdução. Em seguida, apresenta-se a revisão da literatura. Posteriormente, evidenciam-se os aspectos metodológicos, para, na quarta seção, se desenvolver a descrição dos resultados. Por fim apresentam-se as conclusões, limitações e recomendações para futuras investigações.

\section{REFERENCIAL TEÓRICO}

\subsection{Teoria da Tributação Ótima}

A tributação é uma das áreas mais antigas da Contabilidade (Eloy, Soares, \& Casagrande, 2014). Lamb (1995) entende ser função desse ramo científico, registrar todas as operações tributárias exigidas dos contribuintes, de modo que a Ciência Contábil pode tratar os dados e transformálos em informações úteis.

A OECD (2017) produziu um relatório que apresenta o panorama geral das principais tendências em matéria tributária, intitulado "Revenue Statistics 1965-2016", contendo informações divulgadas pelos países com elevada arrecadação tributária. Esse documento revela que as receitas fiscais aumentaram significativamente nos últimos anos, restando, portanto, investigar se o aumento das receitas tem proporcionado maior eficiência dos governos na gestão de seus recursos, e, consequentemente, proporcionado o bem-estar social.

As receitas tributárias, principais fontes de financiamento dos Estados para o desenvolvimento de suas atividades (Ferrer, 2014; Grimm et al., 2009), representam os recursos arrecadados 
pelos governos, registrados nas contabilidades das instituições, e têm como finalidade a realização de gastos que supram as necessidades de uma nação.

Shackelford e Shevlin (2001) classificam a pesquisa contábil na área tributária em coordenação de fatores tributários e não tributários (tradeoffs); efeitos dos tributos sobre os preços dos ativos; tributação multijurisdicional, pesquisa legal e investigação sobre eficiência dos tributos, sendo a última relacionada ao estudo ora desenvolvido. Maydew (2001) faz referência adicional à busca sobre tributação ótima, levando em consideração o fato de que a tributação é considerada ideal, quando utilizada para suprir as necessidades sociais, com o menor custo para a sociedade.

Neste contexto, a Teoria da Tributação Ótima explica que uma política tributária coerente é aquela que se baseia na melhoria do bem-estar social, sem onerar excessivamente os contribuintes de tributos (Payeras, 2008). Na perspectiva de Alm (1996) a tributação ótima decorre de uma aplicação tributária justa e socialmente eficiente, relacionando-se, principalmente, com a capacidade de contribuir com um menor custo para a sociedade (Slemrod \& Yitzhaki, 1996).

Numa linguagem atualizada, Roge e Lennon (2018) mencionam que a relação ótima se dá entre entradas e saídas, significando que, quanto mais unidades de saídas forem obtidas, mais eficiente será o processo. Assim, este artigo classifica como eficientes os países que utilizaram o mínimo de inputs (receitas tributárias) para alcançar o máximo de outputs (indicadores sociais de educação).

Vários estudos usaram a Teoria da Tributação Ótima para avaliar o alcance de níveis elevados de satisfação social, normalmente, divulgados por meio de indicadores (Spadaro, Piccoli, \& Mangiavacchi, 2015; Leroux, Pestieau, \& Ponthiere, 2011; Bruvoll \& Ibenholt, 1998; Stiglitz, 1987; Weymark, 1979; Sandmo, 1978).

Consoante recomendação de Dufrechou (2016) novas pesquisas deverão ser realizadas no sentido de relacionar a gestão fiscal de países com os indicadores sociais, no propósito de investigar se os tributos pagos pela sociedade estão sendo bem administrados e revertidos em benefícios sociais, sem cobrar tributos excessivos da sociedade. Pelo exposto e com suporte na Teoria da Tributação Ótima, este artigo se propõe medir o nível de eficiência dos países-membros da OECD e o Brasil na alocação da receita tributária para a geração de educação.

\subsection{Princípio da Eficiência Pública}

O setor público precisa ser permeado por um sistema de informações e práticas que permitam avaliar a eficiência e, consequentemente, as conquistas sociais. Para isso, impõe-se necessária a produção de dados confiáveis que admitam produzir resultados que auxiliem na redução de desigualdades, transformações, tendências e bem-estar social.

O conceito de eficiência é expresso em investigações contábeis e, de modo geral, destacam a importância de se realizar ações com qualidade, de forma que se alcance resultados satisfatórios. $\mathrm{Na}$ área pública, deve se concentrar na promoção do bem-estar social, todavia, esta finalidade pode não estar sendo atendida por muitos países. No caso da educação, ainda existem milhões de crianças e jovens no mundo que não frequentam a escola (UNESCO, 2017).

A eficiência passou a ser o princípio que dominou o setor público (Hopwood, 1984). Para Miller (1991) a nova concepção permitiu adotar a eficiência com o objetivo de analisar, medir e corrigir as deficiências. Portanto, o princípio da eficiência na área pública consiste na atuação idônea, econômica e satisfatória na administração dos recursos para a realização das finalidades públicas (Modesto, 2000) e está previsto na maior parte das constituições nacionais, sendo dever do Estado suprir as necessidades sociais mais amplas. Firmino (2013, p. 15) afirma que “o princípio da eficiência visa à relação entre os meios e os fins resultante da relação custo-benefício, dos meios empregados de forma ética e dos resultados satisfatórios à sociedade"através da promoção de serviços públicos de qualidade. 
Beuren et al. (2013) mencionam que são poucos os estudos que se têm dedicado a analisar a aplicação do princípio da eficiência no campo da contabilidade. Desta forma, a produção científica nesta área carece de estudos mais aprofundados.

A combinação da Teoria da Tributação Ótima, que explica que o bem-estar social deve ser garantido com a alocação mínima de recursos tributários, com o Princípio da Eficiência Pública, que norteia a aplicação racional de recursos públicos em ações públicas, de maneira a promover o desenvolvimento social, permite embasar o estudo que busca medir o nível de eficiência dos países-membros da OECD e Brasil na alocação da receita tributária para a geração de educação, considerando que países eficientes são aqueles que aplicam o mínimo de recursos para o alcance de resultados educacionais satisfatórios.

Outro fator que justifica a divulgação da eficiência do setor público na maioria das nações é a dificuldade de controles fiscais (Lovre, Ivanovic, \& Mític, 2017).

\subsection{Indicadores de Educação}

O bem-estar educacional é um direito social que deve ser garantido por todas as nações. Domínguez e Ferrero (2003) analisam o bem-estar social sob três abordagens: a) econômica; b) por meio de função de utilidades, e c) medição da assistência social com indicadores sociais sintéticos (Espina \& Arechavala, 2013). Dentre os principais indicadores sociais sintéticos, evidenciam-se o Índice de Desenvolvimento Humano [IDH], outros indicadores relacionados com o desenvolvimento humano do Programa das Nações Unidas para o Desenvolvimento [PNUD], índices educacionais divulgados pela United Nations Educational, Scientific and Cultural Organization [UNESCO] e outros propagados pela OECD.

O IDH constitui medida abreviada de bem-estar social que aquilata a qualidade de vida com base nos parâmetros longevidade (saúde), educação e renda. A dimensão educação é medida delo PNUD considerando dados gerais de escolaridade de diversos países.

A UNESCO divulga informações estatísticas de qualidade para auxiliar os países na análise da eficiência de seus programas relacionados à educação, ciência e tecnologia, cultura e comunicação.

O Programme for International Student Assessment [PISA], desenvolvido pela OECD no ano de 1990, é um dispositivo de avaliação de comparação internacional das performances educacionais (OECD, 2017). Os resultados do PISA demonstram a qualidade e a equidade dos resultados de testes de aprendizagem alcançados pelos Estados-Membros, resumindo o desempenho dos alunos em Ciências, Leitura e Matemática.

Em sua maioria, as pesquisas que mediram a eficiência de países, utilizaram indicadores na área educacional. Navarro-Chavez, Ayvar-Campos e Gimenez-Garcia (2016) analisaram o uso eficiente de recursos para gerar o bem-estar educacional no México no período 1990-2010 utilizando o indicador IDH educação. Amaral, Olenike e Amaral (2015) realizaram estudos para identificar os 30 países com carga tributária mais elevada e o retorno do bem-estar social, incluindo a educação, com base no IDH do ano de 2013 e identificaram como países mais eficientes Austrália, Coreia do Sul, Estados Unidos, Suíça, Irlanda, Japão, Canadá, Nova Zelândia, Israel, Reino Unido, Uruguai, Eslováquia, Espanha, Islândia e Alemanha; enquanto que o Brasil, Finlândia, Dinamarca, Hungria, Itália, Bélgica, França, Áustria, Suécia, Luxemburgo e Eslovênia alcançaram menores eficiências. Wu, Fan e Pan (2014) examinaram a racionalidade do ranque do IDH nos países da OECD. Martín e Mendoza (2013) mediram a qualidade de vida na Espanha utilizando indicadores da OECD. Morais, Miguéis e Camanho (2013) e Lefebvre, Coelli e Pestieau (2010) forneceram uma avaliação de qualidade de vida nas cidades europeias com base em indicadores divulgados pela OECD. Gonzalez, Carcaba, Ventura e Garcia (2011); Hatefi e Torabi (2010) e Murias, Martinez e Miguel (2006) avaliaram o desempenho relativo a países da Ásia e Pacífico em termos de desenvolvimento hu- 
mano utilizando indicadores divulgados pela OECD e IDH. Lee, Lin e Fang (2006), Despotis (2005) e Herrera e Pang (2005) mediram a eficiência dos países desenvolvidos na alocação de despesas à educação utilizando indicadores da OECD e IDH.

Nesta pesquisa, diferentemente das citadas anteriormente, são utilizados conjuntamente, indicadores de educação divulgados pela UNESCO, PNUD e OECD. Tais indicadores revelam o desempenho educacional dos países, que relacionados com a receita tributária permitem observar até que ponto os países cumprem o Princípio da Eficiência Pública e confirmam a Teoria da Tributação Ótima.

\subsection{Pesquisas Anteriores}

Navarro-Chavez et al. (2016) analisaram o uso eficiente dos recursos para ocasionar bemestar no México e concluíram que entidades com maiores recursos não são, necessariamente, as que ensejam maior bem-estar social. Habibov e Fan (2010) recorreram aos créditos fiscais (subvenções governamentais, isenções e reduções tributárias) para comparar o desempenho das províncias canadenses na redução da pobreza. Soares (2019) investigou a eficiência dos estados-membros brasileiros na alocação de recursos públicos para produzir educação no período de 2009 a 2015 e identificou o fato de que as unidades federativas mais eficientes estão localizadas nas regiões com maior arrecadação tributária. Mariano (2012) investigou a eficiência de todos os países e identificou 24 nações eficientes. Maciel, Piza e Penoff (2009) a seu turno, utilizaram as transferências tributárias (tributos arrecadados pelo Governo federal e partilhados entre os entes federados) para analisar a eficiência dos estados-membros brasileiros na efetivação de bem-estar no período 1991-2000.

Experimentou-se a oportunidade de identificar algumas pesquisas que mediram a eficiência de países na área da educação, utilizando, principalmente, a variável "gastos com educação". Bogetoft, Heinesen e Tranaes (2015) investigaram a eficiência dos gastos com educação em alguns países-membros da OECD em 2010 e identificaram o fato de que Noruega, Suécia e Suíça denotaram baixo desempenho nos dispêndios com educação. Os países que se destacaram como eficientes em suas pesquisas foram: Finlândia, Irlanda, Nova Zelândia, Canadá e Estados Unidos. Agasisti (2014) analisou a eficiência da despesa pública na educação em 20 países da Europa no período de 2004 a 2009 e concluiu que não existe relação linear entre os gastos realizados com educação e o desempenho educacional. Baciu e Botezat (2014) sondaram a eficiência no setor público dos paísesmembros da União Europeia no período de 2000 a 2009 e concluíram que essas nações hão de concentrar mais recursos na seara educacional. Agasisti (2011) estudou a eficiência no ensino superior na Europa e apontou a Suíça, Estados Unidos e Reino Unido como eficientes no período de 2000 a 2003. Hauner e Kyobe (2010) mediram a eficiência em educação em 114 países nos anos de 1980 e 2004 e os resultados apontaram que os mais ricos exprimiram melhores desempenhos. Obadić e Aristovnik (2011) pesquisaram a eficiência da despesa com educação nos países-membros da OECD no período de 1999 a 2007 e concluíram que a Croácia foi ineficiente na alocação de gastos com educação, enquanto que os Estados Unidos, Coreia do Sul, Finlândia e Eslováquia foram eficientes, complementando com a ideia de que, se os países cobrarem mais tributos, poderão investir mais em educação. Afonso e Aubyn (2005) mensuraram a eficiência da alocação de despesas com educação e o seu retorno social nos países-membros da OECD e concluíram que a Finlândia, Japão, Coreia do Sul e Suécia são os mais eficientes. Afonso, Schuknecht e Tanzi (2005) avaliaram o Japão, Luxemburgo, Estados Unidos, Austrália, Irlanda, Suíça, Islândia, Reino Unido, Nova Zelândia, Espanha, Portugal e Canadá como os países eficientes em educação no período de 1990 a 2000, enquanto que a Noruega, Grécia, Países Baixos, Alemanha, Áustria, Itália, Bélgica, França, Dinamarca, Finlândia e Suécia foram classificados como ineficientes.

O nosso estudo visa relacionar a arrecadação tributária e os resultados alcançados com educação, objetivando medir o nível de eficiência na alocação destas receitas, a fim de identificar os 
países considerados eficientes e os que necessitam revisar suas ações de políticas educacionais, bem como confirmar o nível de cumprimento do Princípio da Eficiência Pública e explicar a Teoria da Tributação Ótima.

\section{METODOLOGIA}

A presente pesquisa é descritiva, documental quanto aos procedimentos e quantitativa quanto à abordagem do problema.

Um estudo de natureza descritiva é aquele que analisa e interpreta os dados, sem manipulá-los (Marconi \& Lakatos, 2003). No caso, a investigação sob exame verifica o nível de eficiência dos países-membros da OECD e o Brasil na alocação da receita tributária para a geração de educação.

Conforme ensinam Marconi e Lakatos (2003) a pesquisa documental consiste na coleta de dados em fontes primárias, pertencentes a arquivos públicos e particulares de instituições diversas, e vertentes estatísticas. $\mathrm{O}$ estudo analisa os dados divulgados nos relatórios divulgados nos websites da OECD, PNUD e UNESCO, no que se refere aos indicadores educacionais e receitas tributárias, abrangendo o período de 2000 a 2014.

Este estudo usa uma abordagem quantitativa. De acordo com Richardson (1989) esta abordagem caracteriza-se pelo emprego da quantificação, tanto nas modalidades de coleta de dados, quanto no seu tratamento através de técnicas estatísticas. Os resultados da pesquisa foram quantificados por meio de dados matemáticos (DEA), que permite medir a eficiência tributária dos países-membros da OECD e Brasil, e estatísticos (dendograma), que admite relacionar os dados de eficiência com as receitas tributárias.

A população da pesquisa compreende os 35 países da OECD e o Brasil, distribuídos em quatro continentes (Europa, Ásia, Oceania e América). Apesar de o Brasil não fazer parte da OECD, foi incluído em suas pesquisas para fins de comparabilidade.

Relativamente ao período investigado, foram considerados os exercícios financeiros 2000, 2005 e de 2010 a 2014, em virtude da disponibilidade dos dados. Os anos interpolados (2000, 2005 e 2010) foram considerados na pesquisa, para fins de visualização e análise evolutiva do comportamento dos países na aplicação de seus recursos, principalmente o Brasil.

As variáveis utilizadas na pesquisa, demonstradas no Quadro 1, foram revisadas por pares e coletadas no ano de 2017.

Quadro 1 - Variáveis da pesquisa

\begin{tabular}{|c|c|c|}
\hline Variáveis & Natureza/intervalo & Fonte dos dados \\
\hline Receitas tributárias totais (input) & $\begin{array}{l}\text { Em milhões de dólares ameri- } \\
\text { canos, per capita, } \\
\text { e percentagem em relação ao } \\
\text { Produto Interno Bruno [PIB] }\end{array}$ & Website da OECD \\
\hline $\begin{array}{l}\text { Desempenho em leitura e matemática de jovens } \\
\text { com idade mínima de } 15 \text { anos (output) }\end{array}$ & De 0 - 600 (pontuação média) & Website da OECD \\
\hline Índice de educação - IDH (output) & $\begin{array}{c}\text { De } 0 \text { a } 1 \text { (média taxa alfabeti- } \\
\text { zação - } 15 \text { anos ou mais, e taxa } \\
\text { de escolarização) }\end{array}$ & Website do PNUD \\
\hline Escolaridade (output) & Média de anos & Website do PNUD \\
\hline $\begin{array}{l}\text { População com ensino secundário e superior } \\
\text { (output) }\end{array}$ & $\%$ a partir de 25 anos de idade & Website do PNUD \\
\hline $\begin{array}{l}\text { Taxa bruta de matrícula no ensino primário e } \\
\text { secundário (output) }\end{array}$ & $\begin{array}{c}\text { \% bruto da população em } \\
\text { idade escolar primária }\end{array}$ & Website do PNUD \\
\hline Duração de ensino obrigatório (output) & Anos & $\begin{array}{l}\text { Website da UNES- } \\
\text { CO }\end{array}$ \\
\hline
\end{tabular}




\subsection{Métodos e tratamento dos dados}

Assim como nesta investigação, todas as pesquisas citadas nessa seção utilizaram o método DEA para mensurar a eficiência do bem-estar social.

A DEA é uma técnica não paramétrica que aplica a programação linear para comparar unidades tomadoras de decisões DMU as quais realizam tarefas semelhantes com distintas quantidades de insumos (entradas) e bens produzidos (saídas), estabelecendo uma fronteira de eficiência com amparo em dados (Charnes, Cooper \& Rhodes, 1978; Banker, Charnes \& Cooper, 1984). Sua aplicação possibilita medir uma eficiência relativa para cada DMU, permitindo comparar os seus dados de inputs e outputs com outras unidades, quer sejam entidades ou governos (Cooper, Seiford, \& Tone, 2007). Válido é exprimir o fato de que, na demanda agora desenvolvida, os países são analisados como se fossem as unidades produtivas, com vistas a transformar as receitas tributárias produzidas (input) em bem-estar educacional (output).

O método foi desenvolvido em 1978 por Edward Rhodes (Faria, Jannuzzi, \& Silva, 2008) com o objetivo de avaliar a eficiência das escolas públicas dos Estados Unidos, considerando uma série de insumos, entradas ou recursos utilizados e um conjunto de produtos ou saídas gerados por uma unidade (escola). A DEA está demonstrada na Figura 1.

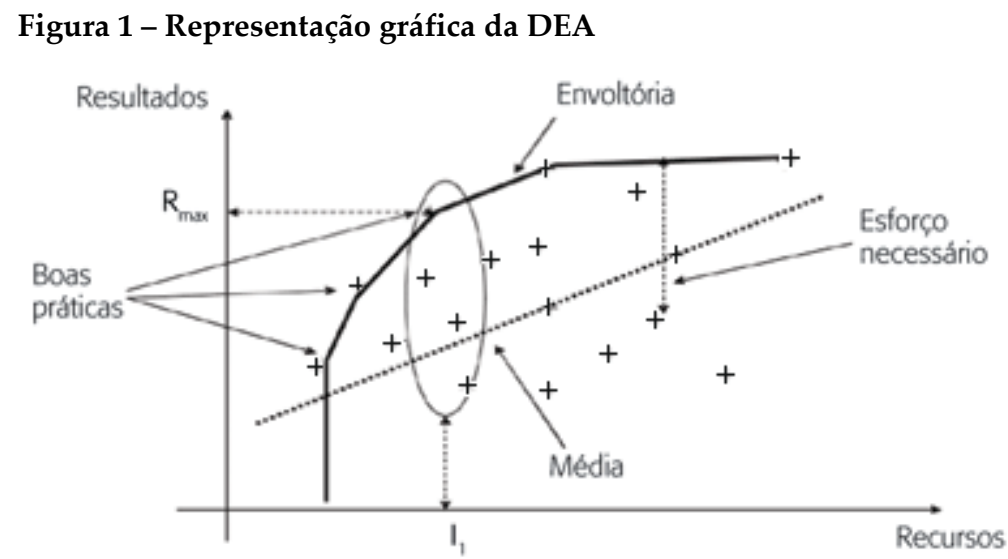

Fonte: Faria et al. (2008)

De acordo com a Figura 1, a fronteira de eficiência relaciona as combinações ótimas de resultados, identificando os casos de boas práticas da gestão dos recursos públicos (Faria et al., 2008).

A literatura aponta a DEA como uma das técnicas a que mais se recorre nas investigações que avaliam a eficiência em educação (Witte \& López-Torres, 2017). Vários autores utilizaram a DEA em trabalhos destinados a medir a eficiência nessa área (Thanassoulis et al., 2016; Bogetoft et al., 2015; Baciu \& Botezat, 2014; Johnson \& Ruggiero, 2014; Thieme, Giménez, \& Prior, 2012; Moreno \& González, 2010; Afonso \& Aubyn, 2005).

A aplicação da DEA é multidimensional, não se restringindo a técnicas direcionadas para recurso único (produto). Os modelos mais conhecidos da DEA são o Charnes, Cooper e Rhodes [CCR] e o Banker, Charnes e Cooper [BCC]. O CCR é oriundo das iniciais dos sobrenomes de seus instituidores e se baseia nos Retornos Constantes de Escala, ou Constant Returns to Scale [CRS] (Charnes et al., 1978), significando que as variações nos inputs proporcionarão variações, na mesma medida, nos outputs. O modelo BCC homenageia os seus criadores e é conhecido como Retornos Variáveis de Escala, ou Variable Returns to Scale [VRS] (Banker et al., 1984), pois considera que a variação dos outputs não precisa ser proporcional aos inputs. Assume-se nesta pesquisa o modelo CCR, amplamente utilizado nas demandas relacionadas à eficiência na geração do bem-estar social, permitindo medir a eficiência, ao se considerar a circunstância de fazer mais com menores re- 
cursos, em consonância com o Princípio da Eficiência Pública. A formulação matemática do modelo básico CCR está descrita no Quadro 2 (Charnes, Rousseau \& Semple, 1996).

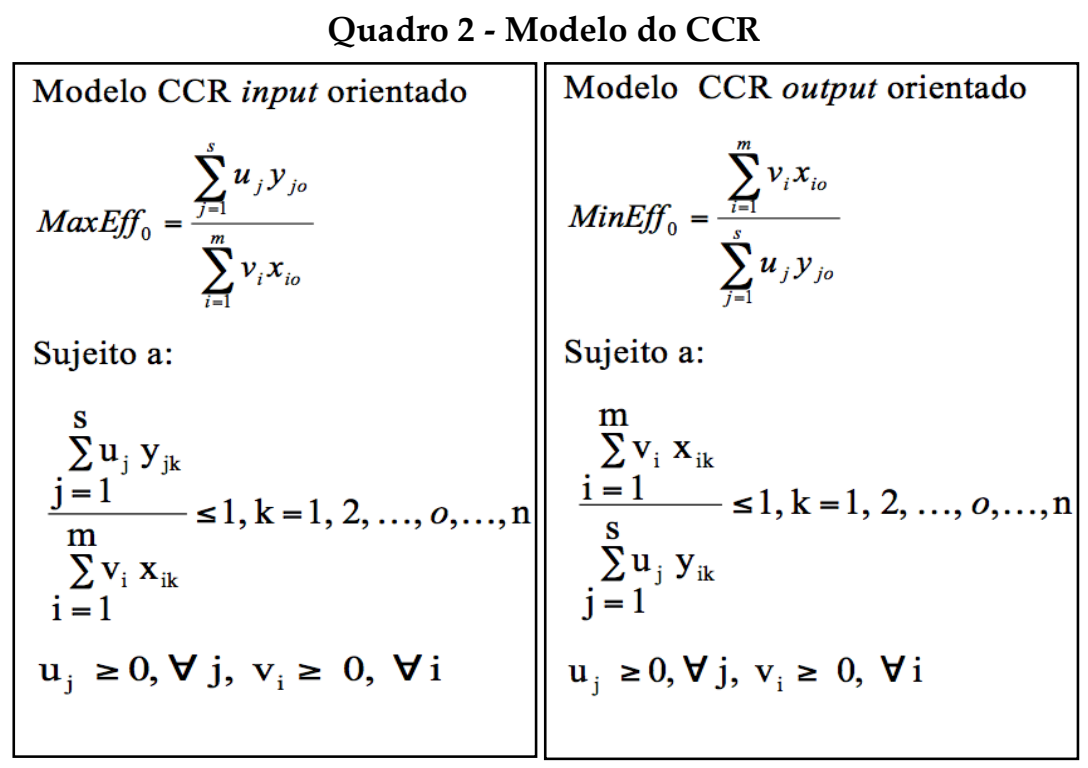

Fonte: Charnes et al. (1996)

No modelo do Quadro 2, $E f f_{0}$ representa a eficiência da $\mathrm{DMU}_{0}$ (país); $u_{j}, v_{i}$ - os pesos de outputs e inputs respectivamente; $x_{i k}, y_{j k}$-inputs i e outputs j da DM $\mathrm{U}_{k}$ e $x_{i 0}, y_{j o}$-inputs i e outputs j da $\mathrm{DMU}_{0}$.

Os inputs selecionados foram as receitas tributárias totais - em milhões de dólares americanos, per capita e percentagem do Produto Interno Bruno [PIB]. Os outputs estão representados pelos indicadores de educação: o índice de educação, média de anos de escolaridade, população com ensino secundário e superior, taxa bruta de matrícula no ensino primário e secundário, duração de ensino obrigatório em anos e desempenho em Leitura e Matemática de jovens com idade mínima de 15 anos.

O resultado obtido por via do modelo varia de 0 a 1 , sendo “0" indicativo de a DMU ser ineficiente, enquanto " 1 " significa que é eficiente.

O segundo método constituído com apoio nos resultados obtidos na DEA é a metodologia hierárquica de Clusters, demonstrada por intermédio do dendograma, resultante da análise estatística de dados, utilizando-se a distância euclidiana. A técnica utilizada, a seu turno, foi a Unweighted Pair Group Method sing Arithmetic Avarages [UPGMA]. Nesta, ligam-se grupos pela média de similaridade entre seus elementos.

Os clusters são subdividos em quatro grupos de países, que se distanciam entre si e com características similares ( $a, b, c$ e d), no que permite validar os resultados do DEA. Os dados analisados na pesquisa foram as receitas tributárias em percentual do PIB e o nível de eficiência (DEA), nos exercícios financeiros 2000, 2005, 2010 a 2014. O Quadro 3 demonstra as características dos clusters e o nível de satisfação da aplicação da receita tributária em favor da educação. 
Quadro 3 - Distribuição dos clusters de acordo com características e nível de satisfação

\begin{tabular}{|c|l|c|}
\hline Cluster & \multicolumn{1}{|c|}{ Características } & Nível de satisfação \\
\hline A & $\begin{array}{l}\text { Alta receita tributária e baixo nível de } \\
\text { eficiência }\end{array}$ & \multicolumn{1}{|c|}{2} \\
\hline B & $\begin{array}{l}\text { Baixa receita tributária e alto nível de efici- } \\
\text { ência }\end{array}$ & 2 \\
\hline C & $\begin{array}{l}\text { Média receita tributária e baixo nível de } \\
\text { eficiência }\end{array}$ & \multicolumn{2}{|c|}{3} \\
\hline D & $\begin{array}{l}\text { Média receita tributária e alto nível de } \\
\text { eficiência }\end{array}$ \\
\hline
\end{tabular}

Fonte: Elaboração própria.

De acordo com o Quadro 3, o nível de satisfação foi classificado sucessivamente de 1 a 4 , onde 4 é formado pelo grupo de países (cluster b) que apresentam os melhores resultados, se confirmando a Teoria da Tributação Ótima e Princípio da Eficiência, enquanto que 1, é formado pelo grupo de países (cluster a) que apresentaram os resultados menos satisfatórios. Em seguida, os dados são distribuídos no gráfico da dispersão, no que permite adicionalmente relacionar a receita tributária em relação ao PIB e o nível de eficiência tributária para a geração de educação.

\section{RESULTADOS}

\subsection{Eficiência tributária para a geração de educação}

O nível de eficiência na aplicação da receita tributária em favor do bem-estar educacional dos países investigados, por ordem de classificação, estão evidenciados na Tabela 1, considerando que, quanto maior for o nível obtido, melhor será a aplicação da carga tributária em favor da educação nos exercícios financeiros 2000, 2005, 2010 a 2014.

Tabela 1 - Nível de eficiência na alocação de receitas tributárias para a geração de educação $(2000,2005,2010$ a 2014$)$

\begin{tabular}{|c|c|c|c|c|c|c|c|c|}
\hline \multirow{2}{*}{ País/Classificação } & \multicolumn{8}{|c|}{ Nível de eficiência (CRS Score) } \\
\hline & 2000 & 2005 & 2010 & 2011 & 2012 & 2013 & 2014 & Média \\
\hline Letônia (1) & 1,00 & 1,00 & 1,00 & 1,00 & 1,00 & 1,00 & 1,00 & 1,00 \\
\hline Coreia do Sul (2) & 1,00 & 1,00 & 1,00 & 0,97 & 0,97 & 1,00 & 1,00 & 0,99 \\
\hline México (3) & 1,00 & 1,00 & 0,97 & 0,99 & 1,00 & 0,98 & 0,96 & 0,99 \\
\hline Chile (4) & 1,00 & 1,00 & 1,00 & 0,93 & 0,91 & 0,99 & 1,00 & 0,97 \\
\hline Estônia (5) & 1,00 & 1,00 & 0,94 & 0,97 & 0,99 & 0,98 & 0,94 & 0,97 \\
\hline Irlanda (6) & 0,79 & 0,87 & 1,00 & 0,99 & 1,00 & 1,00 & 0,98 & 0,95 \\
\hline Islândia (7) & 0,93 & 0,79 & 1,00 & 1,00 & 0,97 & 0,97 & 0,89 & 0,93 \\
\hline Estados Unidos (8) & 0,83 & 0,89 & 1,00 & 0,98 & 0,98 & 0,92 & 0,92 & 0,93 \\
\hline Austrália (9) & 1,00 & 0,83 & 0,94 & 0,92 & 0,91 & 0,89 & 0,90 & 0,91 \\
\hline Suíça (10) & 0,83 & 0,86 & 0,95 & 0,92 & 0,93 & 0,94 & 0,94 & 0,91 \\
\hline Eslováquia (11) & 0,85 & 0,83 & 0,92 & 0,93 & 0,96 & 0,90 & 0,87 & 0,89 \\
\hline Israel (12) & 0,80 & 0,84 & 0,90 & 0,88 & 0,91 & 0,87 & 0,87 & 0,87 \\
\hline Nova Zelândia (13) & 0,90 & 0,78 & 0,91 & 0,90 & 0,85 & 0,87 & 0,84 & 0,86 \\
\hline Luxemburgo (14) & 0,75 & 0,71 & 0,80 & 0,83 & 0,87 & 0,85 & 0,92 & 0,82 \\
\hline Canadá (15) & 0,76 & 0,81 & 0,84 & 0,84 & 0,83 & 0,83 & 0,82 & 0,82 \\
\hline República Checa (16) & 0,86 & 0,80 & 0,81 & 0,79 & 0,78 & 0,77 & 0,80 & 0,80 \\
\hline Japão (17) & 0,82 & 0,80 & 0,83 & 0,81 & 0,80 & 0,78 & 0,75 & 0,80 \\
\hline Eslovênia (18) & 0,79 & 0,72 & 0,75 & 0,76 & 0,76 & 0,77 & 0,78 & 0,76 \\
\hline Polônia (19) & 0,84 & 0,68 & 0,74 & 0,73 & 0,74 & 0,74 & 0,74 & 0,75 \\
\hline Hungria (20) & 0,81 & 0,70 & 0,71 & 0,73 & 0,69 & 0,70 & 0,68 & 0,72 \\
\hline Reino Unido (21) & 0,59 & 0,64 & 0,76 & 0,74 & 0,71 & 0,73 & 0,75 & 0,70 \\
\hline Portugal (22) & 0,71 & 0,65 & 0,70 & 0,66 & 0,69 & 0,70 & 0,68 & 0,69 \\
\hline Espanha (23) & 0,62 & 0,60 & 0,70 & 0,72 & 0,70 & 0,69 & 0,68 & 0,67 \\
\hline Grécia (24) & 0,63 & 0,67 & 0,67 & 0,66 & 0,65 & 0,68 & 0,69 & 0,66 \\
\hline
\end{tabular}

(continua) 


\begin{tabular}{l|llllllll} 
Países Baixos (25) & 0,62 & 0,64 & 0,64 & 0,65 & 0,66 & 0,65 & 0,64 & $\mathbf{0 , 6 4}$ \\
Finlândia (26) & 0,60 & 0,64 & 0,66 & 0,63 & 0,63 & 0,65 & 0,65 & $\mathbf{0 , 6 4}$ \\
Noruega (27) & 0,63 & 0,61 & 0,63 & 0,62 & 0,62 & 0,64 & 0,68 & $\mathbf{0 , 6 3}$ \\
Alemanha (28) & 0,49 & 0,69 & 0,66 & 0,65 & 0,64 & 0,64 & 0,63 & $\mathbf{0 , 6 3}$ \\
Turquia (29) & 0,84 & 0,66 & 0,57 & 0,53 & 0,54 & 0,55 & 0,58 & $\mathbf{0 , 6 1}$ \\
Bélgica (30) & 0,66 & 0,56 & 0,56 & 0,53 & 0,53 & 0,65 & 0,66 & $\mathbf{0 , 5 9}$ \\
Áustria (31) & 0,54 & 0,53 & 0,63 & 0,62 & 0,62 & 0,61 & 0,60 & $\mathbf{0 , 5 9}$ \\
Brasil (32) & 0,94 & 0,71 & 0,50 & 0,49 & 0,48 & 0,48 & 0,49 & $\mathbf{0 , 5 8}$ \\
Suécia (33) & 0,61 & 0,50 & 0,55 & 0,56 & 0,56 & 0,59 & 0,61 & $\mathbf{0 , 5 7}$ \\
Dinamarca (34) & 0,56 & 0,56 & 0,57 & 0,57 & 0,57 & 0,57 & 0,53 & $\mathbf{0 , 5 6}$ \\
França (35) & 0,43 & 0,48 & 0,50 & 0,49 & 0,48 & 0,47 & 0,47 & $\mathbf{0 , 4 7}$ \\
Itália (36) & 0,39 & 0,42 & 0,42 & 0,43 & 0,41 & 0,43 & 0,45 & $\mathbf{0 , 4 2}$ \\
\hline
\end{tabular}

Os dados demonstrados na Tabela 1 revelam que os países classificados nas posições (1) a (18) são os mais eficientes (níveis de 1,00 a 0,76 ) na aplicação da receita tributária em favor da educação (acima da média do grupo), considerando que foram os países que alcançaram os melhores resultados educacionais utilizando o mínimo de recursos, confirmando, portanto, a Teoria da Tributação Ótima (Maydew, 2001) e o cumprimento do Princípio da Eficiência Pública (Firmino, 2013).

Estudos que se assemelharam a esta pesquisa identificaram eficiência na alocação de recursos à educação na Coreia do Sul (Afonso \& Aubyn, 2005; Obadić \& Aristovnik, 2011; Mariano, 2012; Amaral et al., 2015), Estônia (Mariano, 2012), Irlanda (Afonso et al., 2005; Amaral et al., 2015; Bogetoft et al., 2015), Islândia (Afonso et al., 2005; Amaral et al., 2015), Estados Unidos (Afonso et al., 2005; Agasisti, 2011; Obadić \& Aristovnik, 2011; Amaral et al., 2015; Bogetoft et al., 2015), Austrália (Afonso et al., 2005; Mariano, 2012; Amaral et al., 2015), Suíça (Afonso \& Aubyn, 2005; Afonso et al., 2005; Agasisti, 2011; Amaral et al., 2015), Eslováquia (Amaral et al., 2015), Israel (Amaral et al., 2015), Nova Zelândia (Afonso et al., 2005; Amaral et al., 2015; Bogetoft et al., 2015), Canadá (Afonso et al., 2005; Amaral et al., 2015; Bogetoft et al., 2015), República Checa (Mariano, 2012), Japão (Afonso e Aubyn, 2005; Afonso et al., 2005; Amaral et al., 2015; Bogetoft et al., 2015) e Eslovênia (Obadić \& Aristovnik, 2011).

Os países classificados na posição (19) a (36) são os que alcançaram eficiência abaixo da média do grupo (níveis de 0,75 a 0,42), não se confirmando, portanto, a Teoria da Tributação Ótima e o Princípio da Eficiência, uma vez que não aplicaram os recursos tributários com eficiência, para que alcançassem resultados satisfatórios com educação.

As pesquisas anteriores que se assemelham ao estudo identificaram menores eficiências na Grécia (Afonso et al., 2005; Obadić \& Aristovnik, 2011), Finlândia (Afonso et al., 2005; Amaral et al., 2015), Noruega (Afonso et al., 2005; Bogetoft et al., 2015), Alemanha (Afonso et al., 2005), Bélgica (Afonso et al., 2005; Amaral et al., 2015), Áustria (Afonso et al., 2005), Brasil (Amaral et al., 2015), Suécia (Afonso et al., 2005; Bogetoft et al., 2015; Amaral et al., 2015), Dinamarca (Afonso et al., 2005; Amaral et al., 2015), França (Afonso et al., 2005; Amaral et al., 2015) e Itália (Amaral et al., 2015).

A Letônia atendeu plenamente à Teoria da Tributação Ótima (Maydew, 2001) e ao Princípio da Eficiência Pública (Firmino, 2013), pois alcançou nível de eficiência máxima $(1,0)$ em todos os anos investigados, aplicando com excelência os recursos tributários para o alcance de resultados satisfatórios com educação. Enquanto isso, o Brasil se classificou nas últimas posições de eficiência (32), considerando sua alta carga tributária e resultados insatisfatórios com educação. Recebeu, portanto, a pior classificação dentre as nações da América e expressou redução de eficiência ao longo dos anos pesquisados.

Apesar de alguns países, como Alemanha, Noruega, Suécia e Finlândia, terem registrado altos indicadores educacionais, na pesquisa, foram agrupados com menor eficiência, considerando que o volume de receita tributária não foi aplicado de maneira mais eficiente, se comparado com 
os demais países (grupo de eficiência), significando que, se fizessem melhor uso das receitas tributárias, os resultados na qualidade de ensino seriam ainda melhores (Herrera \& Pang, 2005).

Com suporte nos indicadores da Tabela 1, realizou-se o cruzamento dos dados da receita tributária em relação ao PIB, com a eficiência calculada na DEA, recorrendo-se ao método hierárquico dendograma.

\subsection{Distribuição dos países no dendograma}

Na Figura 2 está reproduzido o dendograma, contendo a distribuição dos países por clusters $(a, b, c, e d)$.

Figura 2 - Distribuição dos países no dendograma por clusters

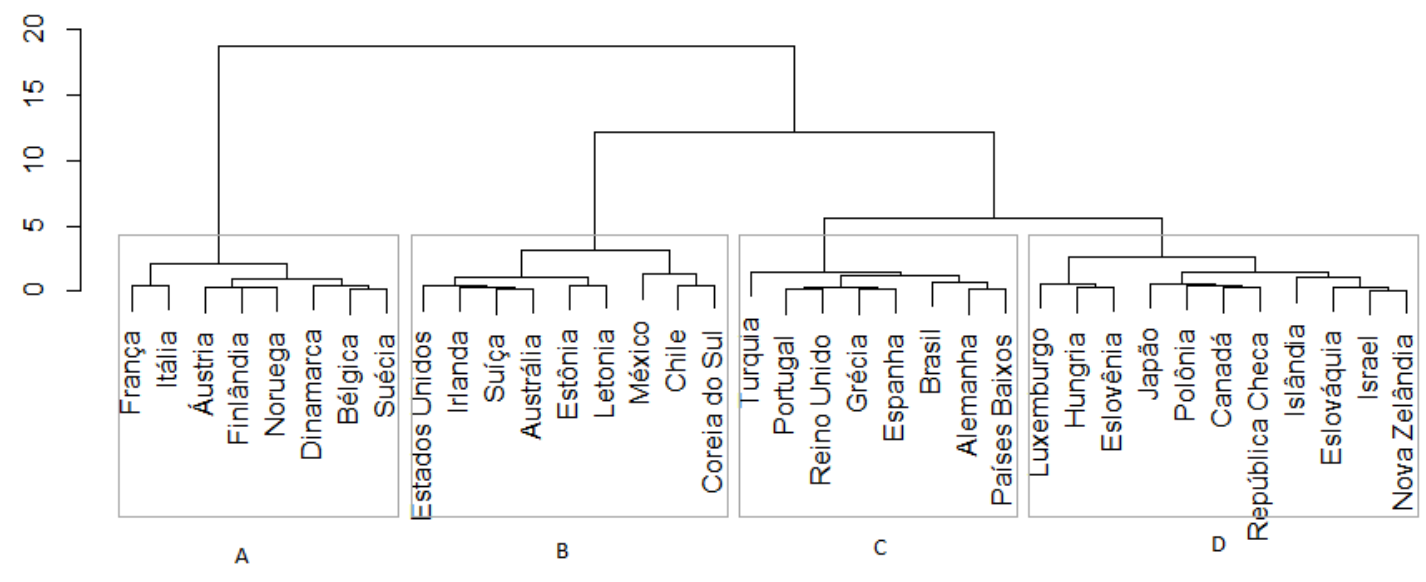

O cluster "a”, formado por França, Itália, Áustria, Finlândia, Noruega, Dinamarca, Bélgica e Suécia, representa o grupo que apresentou o nível de satisfação 1, ou seja, apresentou alta receita tributária e baixo nível de eficiência, evidenciando que a alta arrecadação não impactou na boa administração de recursos aplicados à educação, conforme resultados apresentados na pesquisas de Afonso et al. (2005); Amaral et al. (2015) e Bogetoft et al. 2015. Os resultados apresentados por este grupo, não confirmou a Teoria da Tributação Ótima e o cumprimento do Princípio da Eficiência Pública. O cluster " $b$ " é constituído por Estados Unidos, Irlanda, Austrália, Suíça, Estônia, Letônia, México, Chile e Coreia do Sul, representando o grupo mais eficiente e que alcançou o maior nível de satisfação (4), conforme classificação do Quadro 3, pois, malgrado haver mostrado baixa receita tributária, aplicou-a com qualidade em favor do bem-estar educacional, ou seja, confirmou a explicação da Teoria de Tributação Ótima e o cumprimento do Princípio da Eficiência Pública (Afonso et al., 2005; Agasisti, 2011, Mariano, 2012; Obadić \& Aristovnik, 2011; Amaral et al., 2015; Bogetoft et al., 2015).

O cluster "c" composto por Turquia, Portugal, Reino Unido, Grécia, Espanha, Brasil, Alemanha e Países Baixos, alcançou o nível de satisfação 2, apresentando média receita tributária, se comparado com os demais países investigados, e baixo nível de eficiência, não confirmando, portanto, a Teoria de Tributação Ótima e o cumprimento do Princípio da Eficiência Pública.

O cluster "d" formado por Luxemburgo, Hungria, Eslovênia, Japão, Polônia, Canadá, República Checa, Islândia, Eslováquia, Israel e Nova Zelândia, apresentou alta receita tributária e alto nível de eficiência, se comparado com os demais grupos.

O gráfico de dispersão (Figura 3) demonstra a plotagem da receita tributária em relação ao PIB e os níveis de eficiência (Tabela 1), tomando como base, a média aritmética dos valores reais das duas variáveis, permitindo identificar, adicionalmente, a relação das variáveis. 


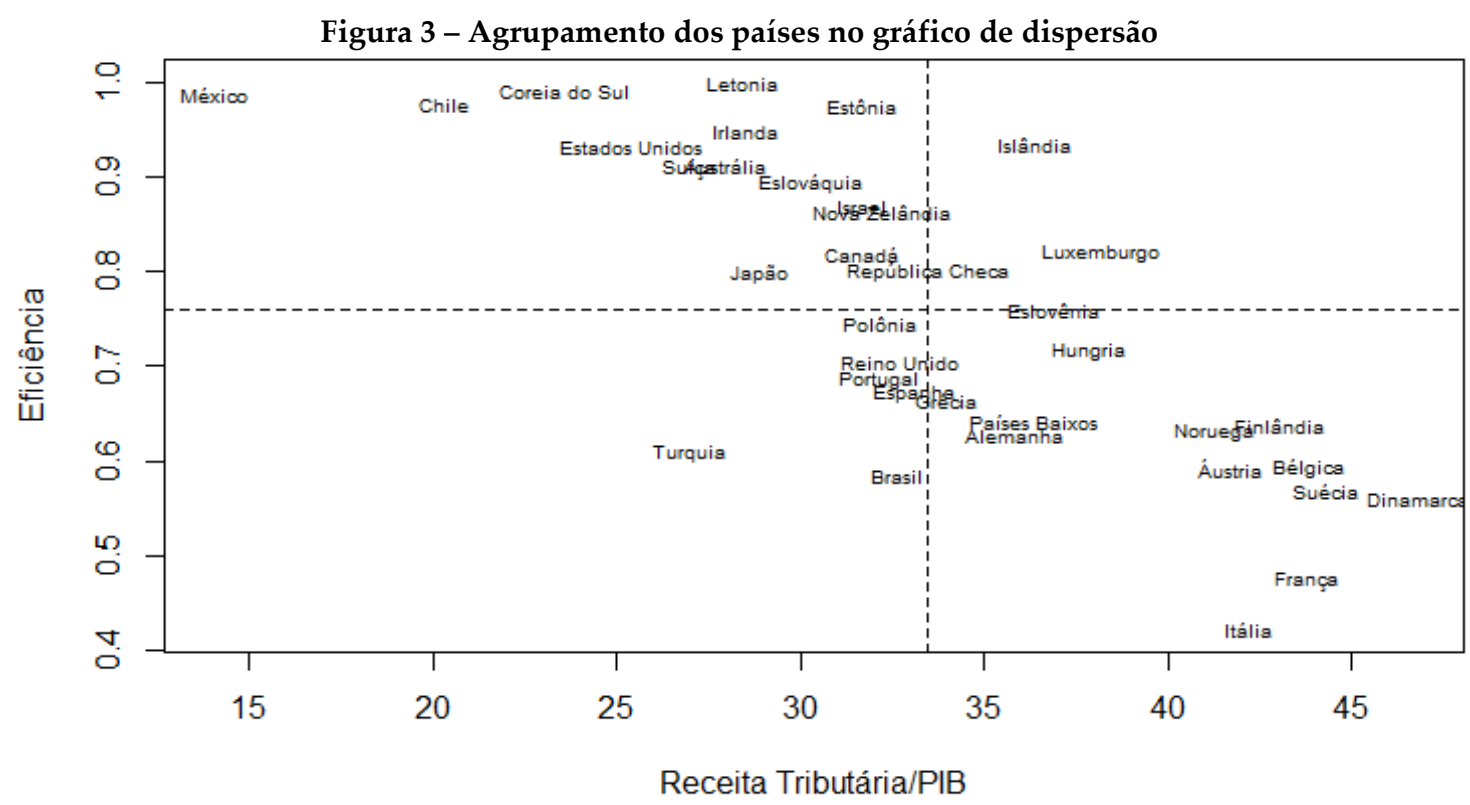

Com amparo nos indicativos revelados na Figura 3, identificam-se os países com maiores receitas tributárias em relação ao PIB e respectiva eficiência de cada um deles na aplicação dos recursos arrecadados em favor da educação.

Na Tabela 2, é apresentada a classificação dos países, por ordem, de maior receita tributária em relação ao PIB e a classificação da eficiência alcançada com a aplicação desses recursos para a geração de educação.

Tabela 2 - Classificação dos países em arrecadação de receitas tributárias em relação ao PIB (\%) e eficiência tributária

\begin{tabular}{|c|c|c|c|c|c|}
\hline País & $\begin{array}{l}\text { Receitas } \\
\text { Tributárias } \\
\text { em } \% \text { do } \\
\text { PIB }\end{array}$ & $\begin{array}{c}\text { Classificação } \\
\text { Eficiência }\end{array}$ & País & $\begin{array}{c}\text { Receitas } \\
\text { Tributárias } \\
\text { em \% do PIB }\end{array}$ & $\begin{array}{c}\text { Classificação } \\
\text { Eficiência }\end{array}$ \\
\hline Dinamarca & $46,75 \%$ & 34 & Brasil & $32,62 \%$ & 32 \\
\hline Suécia & $44,23 \%$ & 33 & Nova Zelândia & $32,16 \%$ & 13 \\
\hline Bélgica & $43,81 \%$ & 30 & Polônia & $32,10 \%$ & 19 \\
\hline França & $43,72 \%$ & 35 & Portugal & $32,09 \%$ & 22 \\
\hline Finlândia & $42,98 \%$ & 26 & Canadá & $31,62 \%$ & 15 \\
\hline Itália & $42,15 \%$ & 36 & Estônia & $31,61 \%$ & 5 \\
\hline Áustria & $41,70 \%$ & 31 & Israel & $31,61 \%$ & 12 \\
\hline Noruega & $41,23 \%$ & 27 & Eslováquia & $30,21 \%$ & 11 \\
\hline Luxemburgo & $38,08 \%$ & 14 & Japão & $28,85 \%$ & 17 \\
\hline Hungria & $37,75 \%$ & 20 & Letônia & $28,39 \%$ & 1 \\
\hline Eslovênia & $36,87 \%$ & 18 & Irlanda & $28,38 \%$ & 6 \\
\hline Países Baixos & $36,37 \%$ & 25 & Austrália & $27,86 \%$ & 9 \\
\hline Islândia & $36,27 \%$ & 7 & Suíça & $26,88 \%$ & 10 \\
\hline Alemanha & $35,74 \%$ & 28 & Turquia & $26,87 \%$ & 29 \\
\hline Grécia & $33,90 \%$ & 24 & Estados Unidos & $25,30 \%$ & 8 \\
\hline Espanha & $33,03 \%$ & 23 & Coreia do Sul & $23,60 \%$ & 2 \\
\hline República Checa & $33,39 \%$ & 16 & Chile & $20,23 \%$ & 4 \\
\hline Reino Unido & $32,64 \%$ & 21 & México & $14,01 \%$ & 3 \\
\hline
\end{tabular}

Fonte: Elaboração própria.

Com base nos dados da Figura 3 e Tabela 2, verifica-se, adicionalmente, que os países com maiores receitas tributárias não são, necessariamente, os mais eficientes na aplicação destes recursos para proporcionar educação. $\mathrm{O}$ resultado assemelha-se aos estudos realizados por NavarroChavez et al. (2016) e Agasisti (2014). 
A relação é apenas confirmada para Islândia e Luxemburgo, considerando que obtiveram alta receita tributária e alcançaram eficiência na alocação desse recurso na geração de educação, atendendo à Teoria da Tributação Ótima e ao Princípio da Eficiência Pública.

Entrementes, Dinamarca, Suécia, Bélgica e França, países com maiores receitas tributárias em relação ao PIB, foram classificados nas últimas posições em eficiência na aplicação desses recursos. Ao contrário, aqueles com menores receitas tributárias, a exemplo de México, Chile, Coreia do Sul e Estados Unidos, compõem o grupo dos mais eficientes na aplicação dos recursos tributários para propiciar o bem-estar educacional, atendendo ao Princípio da Eficiência Pública e à Teoria da Tributação Ótima.

Considerando a relevância dos resultados aqui identificados e o seu impacto social, sugerese a sua divulgação em relatórios e demonstrações contábeis que evidenciem o nível de eficiência dos entes públicos na alocação da receita tributária arrecadada em ações sociais, haja vista, que é função da contabilidade fornecer informações necessárias para a tomada de decisões, prestação de contas e instrumentalização do controle social.

\section{CONSIDERAÇÕES FINAIS}

A investigação ora sob remate objetivou medir o nível de eficiência dos países-membros da OECD e Brasil na alocação da receita tributária para a geração de educação, tendo como base a Teoria da Tributação Ótima e o Princípio da Eficiência Pública.

O esforço investigativo revelou os níveis de eficiência, na ordem de classificação, Letônia, República da Coreia, México, Chile, Estônia, Irlanda, Islândia, Estados Unidos, Austrália, Suíça, Eslováquia, Israel, Nova Zelândia, Luxemburgo, Canadá, República Checa, Japão e Eslovênia como os países que investiram eficientemente a receita tributária em favor da educação, confirmando, portanto, à Teoria da Tributação Ótima e o cumprimento do Princípio da Eficiência Pública.

Os países classificados na DEA - CCR com baixo nível de eficiência (abaixo da média do grupo), cujos resultados não confirmaram a Teoria da Tributação Ótima e o cumprimento do Princípio da Eficiência Pública, figuram na seguinte ordem: Itália, França, Dinamarca, Suécia, Brasil, Áustria, Bélgica, Turquia, Alemanha, Noruega, Finlândia, Países Baixos, Grécia, Espanha, Portugal, Reino Unido, Hungria e Polônia. Essas Nações, por conseguinte, precisam rever suas ações, com vistas ao melhor emprego da arrecadação tributária na promoção do bem-estar educacional, sendo necessário que estes países analisem os motivos que estão impedindo o alcance de resultados satisfatórios.

A Letônia, país com a melhor classificação em eficiência, confirmou plenamente à Teoria da Tributação Ótima e cumpriu o Princípio da Eficiência Pública, pois aplicou com excelência os recursos tributários para a garantia de resultados satisfatórios com educação, servindo, inclusive, de benchmarking para os demais países. Já o Brasil, classificado nas últimas posições de eficiência, não confirmou a Teoria da Tributação Ótima e não cumpriu com o Princípio de Eficiência Pública, decorrente da alta carga tributária e resultados insatisfatórios com educação, cabendo, portanto, rever suas ações com vista a melhorar a eficiência na gestão dos recursos públicos.

Identificou-se, no dendograma, o cluster "a" como o grupo de países que apresentou baixo nível de satisfação, pois apresentou alta receita tributária e baixo nível de eficiência, formado por França, Itália, Áustria, Finlândia, Noruega, Dinamarca, Bélgica e Suécia, fato revelador de que a alta arrecadação tributária não resultou na boa gestão de recursos públicos, não confirmando a Teoria da Tributação Ótima e o cumprindo do Princípio da Eficiência Pública, devendo, revisar suas ações no intuito de alcançar melhores resultados com educação.

O cluster " $b$ ", constante de Estados Unidos, Irlanda, Austrália, Suíça, Estônia, Letônia, México, Chile e Coreia do Sul, representa o conjunto de países que apresentaram maior nível de satisfação, uma vez que apresentou alta eficiência na administração de recursos e baixa receita tributá- 
ria, confirmado, portanto, a Teoria da Tributação ótima e o cumprimento da Eficiência Pública, pois, embora apresente baixo nível de arrecadação tributária, empregou-a com eficiência em favor da educação, não precisando onerar os contribuintes para oferecer serviços públicos de qualidade.

Adicionalmente, a pesquisa revelou que os países com maiores receitas tributárias não são, necessariamente, os mais eficientes na aplicação dessas receitas em favor da educação, confirmando-se somente que Luxemburgo e Islândia aplicam de forma eficiente em despesas de educação a alta receita tributária que arrecadam cumprindo assim a Teoria da Tributação Ótima e o Princípio da Eficiência Pública. A investigação revelou, dissimilis, que os países com menores receitas tributárias, e.g., México, Chile, Coreia do Sul e Estados Unidos, compõem o grupo dos mais eficientes, confirmando a abordagem da Teoria da Tributação Ótima e do Princípio da Eficiência Pública.

Impõe-se exprimir o fato de que este artigo contribuiu para ampliar os estudos de mensuração de eficiência na senda da Contabilidade e fornecer informações relevantes aos gestores públicos, para que possam identificar fragilidades na administração de recursos públicos, visando conquistar melhorias no bem-estar social. Como implicação prática desta pesquisa sugere-se que os demonstrativos contábeis do setor público (nos diferentes níveis de governo) integrem informações sobre o nível de eficiência na aplicação da receita tributária em favor do bem-estar social.

A falta de indicadores educacionais de alguns países investigados no decurso do período examinado provocou limitações nesta pesquisa. Adicionalmente não foi possível utilizar como indicador o valor das receitas tributárias afeto à educação em cada país.

Registra-se como sugestão para futuras pesquisas acadêmicas no terreno da Contabilidade a mensuração da eficiência, implicando no relacionamento das receitas tributárias com indicadores de outras áreas sociais, como saúde, lazer e cultura. Propõe-se, também, que se investigue a eficiência dos estados brasileiros na alocação de recursos públicos para a geração de educação e saúde.

\section{REFERÊNCIAS}

Afonso, A., \& Aubyn, M. S. (2005). Non-Parametric Approaches to Education and Health Efficiency in OECD Countries. Journal of Appled Economic, 2(8), 227-246.

Afonso, A., Schuknecht, L., \& Tanzi, V. (2005). Public sector efficiency: An international comparison. Public Choice, 123(3-4), 321-347.

Agasisti, T. (2011). Performances and spending efficiency in higher education: a European comparison through non-parametric approaches. Education Economics, 19(2), 199-224.

Agasisti, T. (2014). The Efficiency of Public Spending on Education: an empirical comparison of EU countries. European Journal of Education, 49(4), 543-557.

Alm, J. (1996). What is an "optimal” tax system? National Tax Journal, 49(1), 117-133.

Amaral, G. L., Olenike, J. E., \& Amaral, L. M. F. (2015) Cálculo do IRBES: Estudo da Carga Tributária/PIB x IDH. Recuperado em 21 março, 2017, de http://www.ibpt.com.br

Baciu, L., \& Botezat, A. (2014). A Comparative Analysis of the Public Spending Efficiency of the New EU Member States: A DEA Approach. Emerging Markets Finance and Trade 50(4), 31-46.

Banker, R. D., Charnes, A., \& Cooper, W. W. (1984). Some Models for Estimating Technical and Scale Inefficiencies in Data Envelopment Analysis. Management Science, 30(9), 1031-1142. 
Beuren, I. M., Moura, G. D. de, \& Kloeppel, N. R. (2013). Práticas de governança eletrônica e eficiência na utilização das receitas: uma análise nos estados brasileiros. Revista de Administração Pública, 47(2), 421-442.

Bogetoft, P., Heinesen, E., \& Tranaes, T. (2015). The efficiency of educational production: A comparison of the Nordic countries with other OECD countries. Economic Modelling, 50, 310321.

Bruvoll, A., \& Ibenholt, K. (1998). Green Throughput Taxation: Environmental and Economic Consequences. Environmental and Resource Economics, 12(4), 387-401.

Charnes, A., Cooper, W. W., \& Rhodes, E. (1978). A Data Envelopment Analysis Approach to Evaluation of the Program Follow through Experiment in U.S. Public School Education. Management Science Research Report nํㅜ 432. Carnegie-Mellon University, School of Urban and Public Affairs, Pittsburgh, PA.

Charnes, A., Rousseau, J. J., \& Semple, J. H. (1996). Sensitivity and stability of efficiency classifications in Data Envelopment Analysis. Journal of Productivity Analysis, 7(1), 5-18.

Cooper, W. W., Seiford, L. M., \& Tone, K. (2007). Data Envelopment Analysis. Springer US, Boston, MA. doi:10.1007/978-0-387-45283-8.

Despotis, D. K. (2005). Measuring human development via data envelopment analysis: the case of Asia and the Pacific. Omega 33(5), 385-390.

Domínguez, M. A. S., \& Ferrero, N. R. (2003). El bienestar social en los municipios andaluces en 1999. Revista Asturiana de Economia, 27, 99-119.

Dufrechou, P. A. (2016). The efficiency of public education spending in Latin America: A comparison to high-income countries. International Journal of Educational Development, 49, 188-203.

Eloy, A. C. C., Jr., Soares, S. V., \& Casagrande, M. D. H. (2014). A produção científica brasileira sobre Contabilidade tributária em periódicos e eventos no período de 1989-2011. Revista de Contabilidade e Controladoria, 6, 89-102.

Espina, P. Z., \& Arechavala, N. S. (2013). An Assessment of Social Welfare in Spain: Territorial Analysis Using a Synthetic Welfare Indicator. Social Indicators Research, 111, 1-23.

Faria, F. P., Jannuzzi, P. de M., \& Silva, S. J. (2008). Efficiency of municipal expenditure in health and education: an investigation using data envelopment analysis in the state of Rio de Janeiro, Brazil. Revista de Administração Pública, 42, 155-177.

Ferrer, V. E. J. (2014). Medición del desarrollo humano: un índice alternativo al IDH-2010. Especial referencia a los países latinoamericanos. Investigación Económica 73(228), 87-115.

Firmino, R. G. (2013). Avaliação da eficiência na aplicação dos recursos públicos da educação básica: um estudo nos municípios paraibanos. Dissertação de mestrado, Universidade Federal da Paraíba, João Pessoa, PB, Brasil. Disponível: http://repositorio.unb.br/handle/10482/13113 
Gonzalez, E., Carcaba, A., Ventura, J., \& Garcia, J. (2011). Measuring Quality of Life in Spanish Municipalities. Local Government Studies, 37(2), 171-197.

Grimm, M., Harttgen, K., Klasen, S., Misselhorn, M., Munzi, \& T., Smeeding, T. (2009). Inequality in Human Development: An empirical assessment of thirty-two countries. Social Indicators Research 97(2), 191-211.

Habibov, N. N., \& Fan, L. (2010). Comparing and contrasting poverty reduction performance of social welfare programs across jurisdictions in Canada using Data Envelopment Analysis (DEA): an exploratory study of the era of devolution. Evolution and Program Planning, 33, 457-467.

Hatefi, S. M., \& Torabi, S. A. (2010). A common weight MCDA-DEA approach to construct composite indicators. Ecological Economics, 70, 114-120.

Hauner, D., \& Kyobe, A. (2010). Determinants of Government Efficiency. World Development, $38(11), 1527-1542$.

Herrera, S., \& Pang, G. (2005). Efficiency of public spending in developing countries : an efficiency frontier approach (SSRN Scholarly Paper No. ID 922917). Social Science Research Network, Rochester, NY.

Hopwood, A. G. (1984). Accounting and the pursuit of efficiency, in Public Sector Accounting, Philip Allan, Oxford, 167-187.

Johnson, A. L., \& Ruggiero, J., (2014). Nonparametric measurement of productivity and efficiency in education. Annals of Operations Research, 221, 197-210.

Lamb, M. (1995). When is a group a group? Convergence of concepts of ' group' in Union corporate tax. Journal European Accounting Review, 4, 33-80.

Lee, H. S., Lin, K., \& Fang, H. H. (2006). A fuzzy multiple objective DEA for the human development index, in: Gabrys B., Howlett R. J., Jain L. C. (Eds) Knowledge-Based Intelligent Information and Engineering Systems. KES 2006. Lecture Notes in Computer Science (vol. 4252). Berlin, Heidelberg: Springer.

Lefebvre, M., Coelli, T., \& Pestieau, P. (2010). On the Convergence of Social Protection Performance in the European Union. CESifo Economic Studies, 56(2), 300-322.

Leroux, M. L., Pestieau, P., \& Ponthiere, G. (2011). Longevity, genes and efforts: An optimal taxation approach to prevention. Journal of Health Economics, 30, 62-76.

Lovre, I., Ivanovic, O. M, \& Mític, P. (2017). Analysis of Public Sector Efficiency in Developed Countries. Economic Analysis, 50(1,2), 38-49.

Maciel, V. F., Piza, C. C. de T., \& Penoff, R. N. (2009). Desigualdades Regionais e Bem-Estar no Brasil: Quão Eficiente tem Sido a Atividade Tributária dos Estados para a Sociedade?. Planejamento e Políticas Públicas, 33, 291-318. 
Marconi, M. A., \& Lakatos, E. M. (2003). Fundamentos de metodologia científica (5. ed.). São Paulo: Atlas.

Mariano, E. B. (2012). Crescimento econômico e desenvolvimento humano: uma análise mundial da eficiência social de Estados-nação. Tese de doutorado. Universidade de São Paulo, SP, Brasil. Disponível: http://teses.usp.br/teses/disponiveis/18/18157/tde-24082012-142856/

Martín, J. C., \& Mendoza, C. (2013). A DEA Approach to Measure the Quality-of-Life in the Municipalities of the Canary Islands. Social Indicators Research, 113, 335-353.

Maydew, E. L. (2001). Empirical tax research in accounting: A discussion. Journal of Accounting and Economics, 31(1-3), 389-403.

Miller, P. (1991). Accounting innovation beyond the enterprise: problematizing investment decisions and programming economic growth in the UK in the 1960s. Accounting, Organizations and Society, 16(8), 733-762.

Modesto, P. (2000). Notas para um debate sobre o princípio da eficiência. Revisto do Serviço Público $51(2), 105-119$.

Morais, P., Miguéis, V. L., \& Camanho, A. S. (2013). Quality of Life Experienced by Human Capital: An Assessment of European Cities. Social Indicators Research, 110, 187-206.

Moreno, J. D. J., \& González, D. S. (2010). Los Determinantes de la eficiencia educativa en la Unión Europea. Revista de Economia Pública, 193(2), 131-156.

Murias, P., Martinez, F., \& Miguel, C. D. (2006). An Economic Wellbeing Index for the Spanish Provinces: A Data Envelopment Analysis Approach. Social Indicators Research, 77(3), 395417.

Navarro-Chavez., J. C., Ayvar-Campos., J. F., \& Gimenez-Garcia., M. V. (2016). Generation of social welfare in Mexico: A DEA study from HDI. Economía, Sociedad y Territorio, 52(15), 591-621.

Obadić, A., \& Aristovnik, A. (2011). Relative Efficiency of higher education in Croatia and Slovenia: Na International comparison. Amfiteatru Economic Journal, 30(13), 362-276.

Organization for Economic Cooperation and Development. (2017). Revenue Statistics - OECD Countries: Comparative tables. Recuperado em 21 janeiro, 2017 de https://stats.oecd.org/Index.aspx?DataSetCode=REV

Payeras, J. A. P. (2008). A carga tributária no Brasil e sua distribuição. Tese de doutorado, Universidade de São Paulo, São Paulo, SP, Brasil. Disponível: http://teses.usp.br/teses/disponiveis/11/11132/tde-12082008-115340/pt-br.php

Programa das Nações Unidas para o Desenvolvimento. (2013). Relatório do Desenvolvimento Humano. A Ascensão do Sul: Progresso Humano num Mundo Diversificado. Recuperado em 27 abril, 2017, de http://www.br.undp.org/content/brazil/pt/home/library/relatorios-dedesenvolvimento-humano/relatorio-do-desenvolvimento-humano-200012.html 
Programa das Nações Unidas para o Desenvolvimento. (2017). Human Develpment Data (19902015). Recuperado em 23 abril, 2017, de http://hdr.undp.org/en/data

Rezende, A. J., Slomski, V., \& Corrar, L. J. (2005). A gestão pública municipal e a eficiência dos gastos públicos: uma investigação empírica entre as políticas públicas e o índice de desenvolvimento humano (IDH) dos municípios do estado de São Paulo. Revista Universo Contábil, 1, $24-40$.

Richardson, R. J. (1989). Pesquisa social: métodos e técnicas. São Paulo: Atlas.

Roge, K. M., \& Lennon, N. J. (2018). A study on the criteria of internal transparency, efficiency and effectiveness inmeasuring local government performance. Financial, Accounting \& Management, 34, 392-409.

Sandmo, A. (1978). Direct versus indirect pigovian taxation. European Economic Review, 7(4), 337349.

Schachter, H. L. (2007). Does Frederick Taylor's Ghost Still Haunt the Halls of Government? A Look at the Concept of Governmental Efficiency in Our Time. Public Admistration Review, 67(5), 800-810.

Shackelford, D. A., \& Shevlin, T. (2001). Empirical tax research in accounting. Journal of Accounting Economics, 31(1-3), 321-387.

Slemrod, J., \& Yitzhaki, S. (1996). The Costs of Taxation and the Marginal Efficiency Cost of Funds. Staff Papers, 43, 172-198.

Soares, M. F. (2019). O princípio da eficiência em Contabilidade pública: a alocação de recursos públicos para a geração de educação e saúde nos estados brasileiros. Tese de doutorado. Universidade do Minho, Braga, Portugal. Disponível: http: //repositorium.sdum.uminho.pt/handle/1822/62621

Spadaro, A., Piccoli, L., \& Mangiavacchi, L. (2015). Optimal Taxation, Social Preferences and the Four Worlds of Welfare Capitalism in Europe. Economica, 82, 448-485.

Stiglitz, J. E. (1987). Chapter 15 Pareto efficient and optimal taxation and the new new welfare economics. Handbook of Public Economics, 2, 991-1042.

Thanassoulis, E., Witte, K. D., Johnes, J., Johnes, G., Karagiannis, G., \& Portela, C.S. (2016). Applications of Data Envelopment Analysis in Education, in: Zhu, J. (Ed.), Data Envelopment Analysis, International Series in Operations Research \& Management Science. Springer US, 367-438.

Thieme, C., Giménez, V., \& Prior, D. (2012). A comparative analysis of the efficiency of national education systems. Asia Pacific Education Review, 13, 1-15. 
United Nations Educational, Scientific and Cultural Organization. (2017). Education for All Movemente. Recuperado em 10 abril, 2017, de http://www.unesco.org/new/en/education/themes/leading-the-internationalagenda/education-for-all

Weymark, J. A. (1979). A reconciliation of recent results in optimal taxation theory. Journal of Public Economics, 12(2), 171-189.

Witte, K. D., \& López-Torres, L. (2017). Efficiency in education: a review of literature and a way forward. Journal of the Operational Research Society, 68(4), 339-363.

Wu, P. C., Fan, C. W., \& Pan, S.C. (2014). Does Human Development Index Provide Rational Development Rankings? Evidence from Efficiency Rankings in Super Efficiency Model. Social Indicators Research, 116(2), 647-658. 